\title{
Dopamine Inhibits High-Frequency Stimulation- Induced Long-Term Potentiation of Intrinsic Excitability in CA1 Hippocampal Pyramidal Neurons
}

\author{
Chun-ling Wei Yi-hui Liu Ming-hao Yang Zhi-qiang Liu Wei Ren \\ Key Laboratory of MOE for Modern Teaching Technology and College of Life Sciences, Shaanxi Normal University, \\ Xi'an, China
}

\section{Key Words}

Dopamine $\cdot$ Intrinsic plasticity $\cdot$ Hippocampus

\begin{abstract}
The efficiency of neural circuits is modified by changes not only in synaptic strength, but also in intrinsic excitability of neurons. In CA1 hippocampal pyramidal neurons, bidirectional changes in the intrinsic excitability are often presented after induction of synaptic long-term potentiation or depression. This plasticity of intrinsic excitability has been identified as a cellular correlate of learning. Besides, behavioral learning often involves action of reinforcement or rewarding mediated by dopamine (DA). Here, we examined how DA influences the intrinsic plasticity of CA1 hippocampal pyramidal neurons when high-frequency stimulation (HFS) was applied to Schaffer collaterals. The results showed that DA inhibits the decrease in rheobase and increase in mean firing rate of pyramidal neurons induced by HFS, and that this inhibition was abolished by the $\mathrm{D}_{1}$-like receptor antagonist $\mathrm{SCH} 23390$ but not by the $\mathrm{D}_{2}$-like receptor antagonist sulpiride. The results suggest that DA inhibits the potentiation of excitability induced by presynaptic HFS, and that this inhibition depends on the activation of $D_{1}$-like receptors.
\end{abstract}

Copyright $\odot 2012$ S. Karger AG, Basel

\begin{tabular}{ll}
\hline KARGER & $\begin{array}{l}\text { ( } 2012 \text { S. Karger AG, Basel } \\
1424-862 X / 13 / 0214-0150 \$ 38.00 / 0 \quad \text { Karger }\end{array}$ \\
E-Mail karger@karger.com & $\begin{array}{l}\text { This is an Open Access article licensed under the terms of the } \\
\text { www.karger.com/nsg }\end{array}$ \\
& $\begin{array}{l}\text { Creative Commons Attribution-NonCommercial 3.0 Un- } \\
\text { ported license (CC BY-NC) (www.karger.com/OA-license), } \\
\text { applicable to the online version of the article only. Distribu- } \\
\text { tion permitted for non-commercial purposes only. }\end{array}$
\end{tabular}

\section{Introduction}

Although synaptic plasticity has been considered the best candidate mechanism for the formation and storage of memories, more and more attention has been given to activity-dependent changes in the intrinsic excitability of neurons [1-13]. Since its original description, the induction of synaptic long-term potentiation (LTP) has been known to be accompanied by a lasting increase in the intrinsic excitability of hippocampal neurons [14]. This activity-dependent intrinsic plasticity has been suggested to be the other side of the engram for learning and memory $[5,10,13,15-18]$.

Behavioral learning often involves reward processes. In such learning, the activity of dopamine (DA) neurons has been shown to encode prediction error and uncertainty [19]. Animal experiments have shown that blockade of DA receptors impairs learning and memory, and DA receptor agonists can improve learning and memory $[20,21]$. The hippocampus, a brain region that receives extensive dopaminergic projections from mesolimbic structures such as the ventral tegmental area and substantia nigra [22, 23], has a key role in learning and memory $[24,25]$. The effects of DA in the hippocampus are multiple: the transmitter inhibits the excitability of pyra-

Yi-hui Liu, PhD

Key Laboratory of MOE for Modern Teaching Technology

Shaanxi Normal University

Xi'an 710062 (China)

E-Mail liu.y.hui@gmail.com 
midal neurons [26-31] while it facilitates LTP [32-34] in the hippocampus. The effects of DA on long-term depression in the hippocampus have been less clear. The activation of $\mathrm{D}_{1}$-like DA receptors was found to facilitate longterm depression in some experiments $[32,35]$ but to reverse it in others [34,36].

Although the effects of DA on excitability and synaptic plasticity have been extensively investigated in the hippocampus, little is known about whether the DA system interacts with the activity-dependent intrinsic plasticity. Here we use whole-cell patch clamp recording to study whether the intrinsic plasticity induced by high-frequency stimulation (HFS) is modified by bath application of DA. The results showed that DA application inhibits the potentiation of excitability in CA1 pyramidal neurons induced by HFS on Schaffer collaterals, and that this inhibition depends on the activation of $\mathrm{D}_{1}$-like receptors.

\section{Materials and Methods}

\section{Animal Treatment}

All procedures were performed in accordance with the institutional guidelines for the care and use of laboratory animals as approved by the Animal Care Committee of Shaanxi Normal University.

\section{Electrophysiology}

Slice Preparation. Brain slices were prepared as reported previously [8]. Briefly, 10- to 17-day-old Sprague-Dawley rats were anesthetized with pentobarbitone sodium $(55 \mathrm{mg} / \mathrm{kg})$ and decapitated. Brains were removed rapidly and glued with the anterior surface down. Transverse brain slices of $300 \mu \mathrm{m}$ were cut with a vibratome (1,000 plus; Vibratome Company, USA). Slices containing the hippocampus were incubated in the slice solution gassed with $5 \% \mathrm{CO}_{2}$ and $95 \% \mathrm{O}_{2}$ for $1-3 \mathrm{~h}$ and then transferred to a recording chamber $(1.5 \mathrm{ml})$ that was perfused with the slice solution gassed with $5 \% \mathrm{CO}_{2}$ and $95 \% \mathrm{O}_{2}$ at room temperature (23$25^{\circ} \mathrm{C}$ ) for recording. The standard slice solution contained (in $\mathrm{mM}): 126 \mathrm{NaCl}, 2.5 \mathrm{KCl}, 1.25 \mathrm{NaH}_{2} \mathrm{PO}_{4}, 2 \mathrm{MgCl}_{2}, 2 \mathrm{CaCl}_{2}, 10$ glucose, $26 \mathrm{NaHCO}_{3}$, pH 7.4, when gassed with $5 \% \mathrm{CO}_{2}$ and $95 \% \mathrm{O}_{2}$.

Whole-Cell Patch Clamp Recording. Cells were visualized with a $\times 40$ water immersion lens on a Leica DM LFSA upright microscope (Leica, Germany) equipped with differential interference contrast optics. Patch electrodes with a resistance of 4-7 M $\Omega$ for somatic recordings were pulled from glass capillaries using a P-97 electrode puller (Sutter Instruments, Novato, Calif., USA) and polished by an MF-830 microforge (Narishige, Japan). Cells with the seal resistance $<1.2 \mathrm{G} \Omega$ and a resting membrane potential more positive than $-63 \mathrm{mV}$ were rejected. Pyramidal neurons were patched in either the voltage clamp or the current clamp configuration. The pipette solution for whole-cell recordings contained (in mM): $120 \mathrm{~K}$-gluconate, $20 \mathrm{KCl}, 2 \mathrm{MgCl}_{2}, 10 \mathrm{HEPES}, 0.2$ EGTA, $4 \mathrm{Na}_{2}$ ATP, $0.3 \mathrm{Na}_{3} \mathrm{GTP}$, and 7 phosphocreatine, $\mathrm{pH}$ adjusted to 7.2 with $\mathrm{KOH}$. A Multiclamp 700B amplifier (Axon Instruments, USA) was used to perform whole-cell recordings.

Dopamine Inhibits HFS-Induced LTP of

Intrinsic Excitability
Conditional Stimulus. To evoke presynaptic glutamate release, a concentric bipolar stimulating electrode (CBARC75, FHC) was placed in the stratum $100-200 \mu \mathrm{m}$ from the soma of recorded pyramidal neurons to deliver extracellular stimulation to the Schaffer collateral pathway. Stimuli were delivered by a Grass S88X stimulator via a Grass SIU isolation unit (Grass Instruments, Quincy, Mass., USA). The intensity of HFS was set as the minimal test stimulus intensity that could induce the maximal amplitude of the Schaffer collateral-CA1 synaptic response. The duration of each pulse was $0.1 \mathrm{~ms}$. Three trains of 100 pulses at $100 \mathrm{~Hz}$ were delivered with an intertrain interval of $20 \mathrm{~s}$.

\section{Data Analysis}

Recorded signals were sampled at $10 \mathrm{kHz}$ by pClamp 10.2 software (Axon Instruments, USA). Analyzed data were further processed with Origin 8.0 (Microcal Software, USA) and SPSS 15.0 (IBM SPSS, USA). Statistical data are presented as means \pm SEM. Repeated measures analysis of variance (ANOVA) and Student's $t$ test were used to examine statistical significance. $p$ values less than 0.05 were considered to be significant.

\section{Results}

\section{HFS Induced an Increase in Excitability}

Whole-cell patch clamp recordings were performed in CA1 pyramidal neurons from acutely isolated hippocampal slices. The conditional stimulus used in this study was an HFS which consisted of 3 trains of 100 pulses at 100 $\mathrm{Hz}$ with an intertrain interval of $20 \mathrm{~s}$. To study intrinsic excitability, step current injections were applied to the soma of hippocampal CA1 pyramidal neurons before and after HFS application. The membrane potential of pyramidal neuron soma was recorded, and rheobase and mean firing rate were analyzed to measure intrinsic excitability (fig. 1).

Under the control conditions, the resting membrane potential of CA1 pyramidal neurons was $-68.3 \pm 0.57$ $\mathrm{mV}$. After HFS, the resting potential did not change $(\mathrm{p}=$ $0.2485,0.5518,0.7193,0.4172$ for $15,30,45,60 \mathrm{~min}$ vs. control; paired t test, $\mathrm{n}=16$ cells; fig. $1 \mathrm{~b})$.

Intrinsic excitability of a neuron can be assessed with rheobase, which is defined as the minimal current injection needed to evoke a spike. Under the control conditions, the rheobase of hippocampal pyramidal neurons was $76.3 \pm 4.6 \mathrm{pA}$. HFS induced a persistent decrease in the rheobase of pyramidal neurons $(65.0 \pm 5.0 \mathrm{pA}$ at 15 min after HFS). The decrease became significant at 15 min after application of HFS (fig. $1 b ; p=0.0028,0.0005$, $0.0002,0.0000$ for $15,30,45,60$ min vs. control; paired $t$ test, $\mathrm{n}=16$ cells).

The total membrane conductance, called input resistance, measures the asymptotic sensitivity of the mem- 


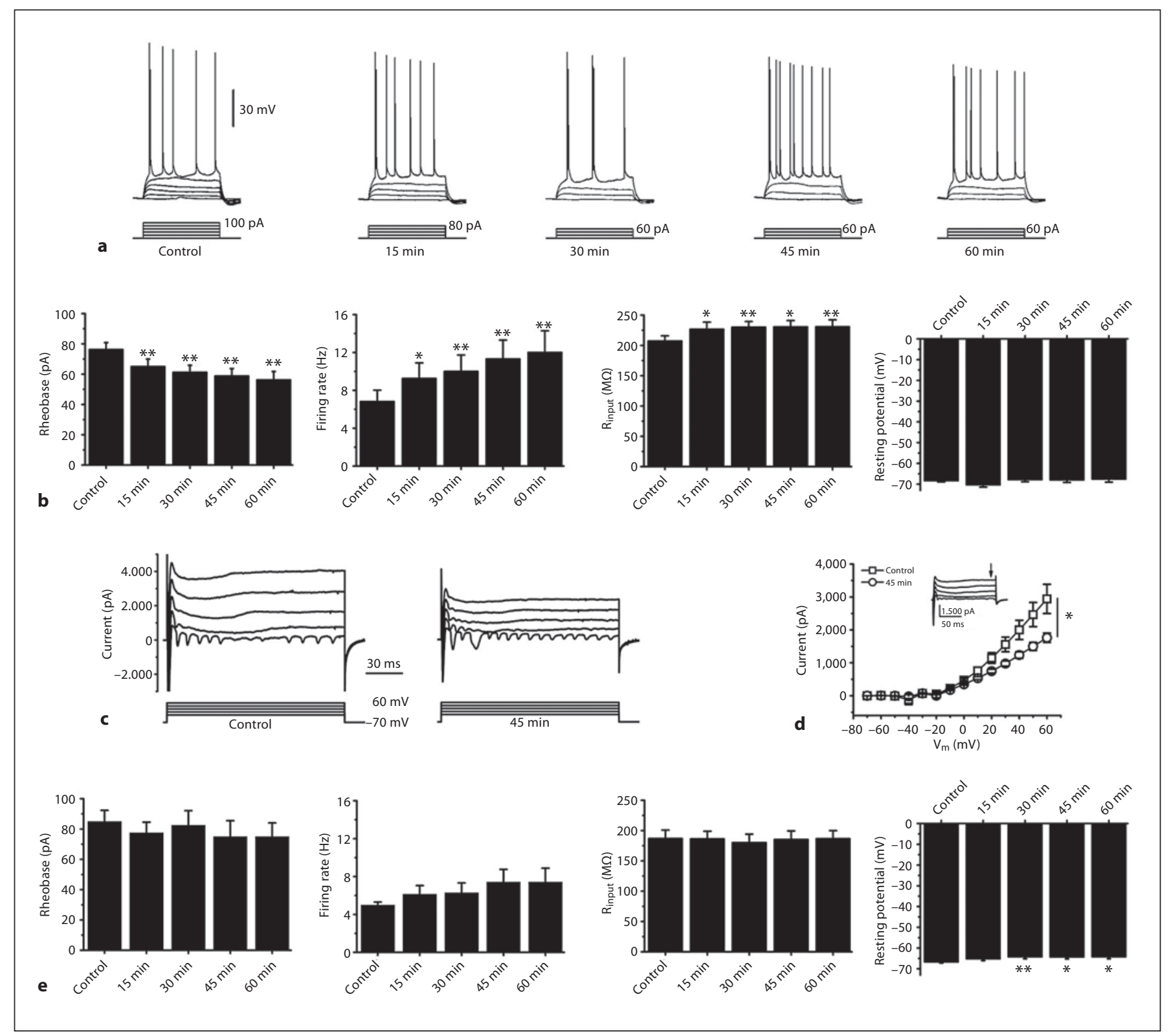

Fig. 1. HFS-induced increase in excitability. a Whole-cell current clamp recordings from a representative pyramidal neuron showing HFS-induced decrease in rheobase and increase in mean firing rate. Bottom lines show injected currents (in picoamperes). b Statistics of rheobase, firing rate, input resistance $\left(\mathrm{R}_{\text {input }}\right)$ and resting membrane potential. The rheobase decreased $15 \mathrm{~min}$ after application of HFS. The mean firing rate evoked by $100 \mathrm{pA}$ current injection increased $15 \mathrm{~min}$ after HFS induction. The input resistance increased $15 \mathrm{~min}$ after HFS. The resting membrane potential remained unchanged. ${ }^{*} \mathrm{p}<0.05,{ }^{* *} \mathrm{p}<0.01$; paired t test, compared to control, $\mathrm{n}=16$. $\mathrm{c}$ Whole-cell voltage clamp record- ings from a representative pyramidal neuron showing whole current before (left) and 45 min after (right) HFS induction. Bottom lines show holding potentials (in millivolts). d Statistics of 16 neurons showing the steady-state whole current I-V relation measured before and 45 min after HFS induction. ${ }^{*} \mathrm{p}<0.05$, repeated measures ANOVA, $\mathrm{n}=16$. Inset Whole-cell voltage clamp recordings of the steady-state whole current. e In the absence of HFS induction, rheobase, mean firing rate and input resistance remained stable within $60 \mathrm{~min}$ and the resting membrane potential was slightly depolarized after $30 \mathrm{~min}$ of patching. ${ }^{*} \mathrm{p}<0.05$, ${ }^{* *} \mathrm{p}<0.01$; paired t test, $\mathrm{n}=10$. 
brane potential to injected or intrinsic currents, and is reciprocally related to the rheobase. Under the control conditions, the input resistance of hippocampal pyramidal neurons was $207.2 \pm 8.7 \mathrm{M} \Omega$. HFS induced a persistent increase in the input resistance $(226.6 \pm 11.7 \mathrm{M} \Omega$ at 15 min after HFS). The increase became significant at 15 min after application of HFS (fig. 1b; $\mathrm{p}=0.0252,0.0047$, $0.0120,0.0085$ for $15,30,45,60 \mathrm{~min}$ vs. control; paired $\mathrm{t}$ test, $\mathrm{n}=16$ cells).

When $100 \mathrm{pA}$ current injection, which was sufficient to evoke spikes in all neurons we recorded, was applied to the neuron soma, the mean firing rate was $6.8 \pm 1.2 \mathrm{~Hz}$. HFS induced a persistent increase in the mean firing rate $(9.3 \pm 1.6 \mathrm{~Hz}$ at $15 \mathrm{~min}$ after HFS). The increase became significant at $15 \mathrm{~min}$ after application of HFS $(\mathrm{p}=0.0135$, $0.0046,0.0010,0.0015$ for $15,30,45,60$ min vs. control; paired t test, $\mathrm{n}=16$ cells; fig. $1 \mathrm{~b})$. Both decrease in rheobase and increase in mean firing rate suggest an increase in intrinsic excitability after HFS, which is consistent with previous works.

In the absence of HFS induction, there was no significant change in rheobase and mean firing rate (fig. 1e; rheobase: $\mathrm{p}=0.0800,0.5983,0.1705,0.1036$ for $15,30,45,60$ min vs. control; mean firing rate: $\mathrm{p}=0.1879,0.2530,0.1205$, 0.1551 for $15,30,45,60$ min vs. control; paired t test, $\mathrm{n}=$ 10 cells). Consistent with the rheobase, input resistance was not changed ( $p=0.9276,0.1448,0.7470,0.9601$ for 15 , $30,45,60$ min vs. control; paired t test, $\mathrm{n}=10$ cells). The resting membrane potential is slightly depolarized (control: $-66.63 \pm 0.59 \mathrm{mV}, 15 \mathrm{~min}:-65.13 \pm 0.94 \mathrm{mV}, 30 \mathrm{~min}$ : $-64.18 \pm 0.99 \mathrm{mV}, 45 \mathrm{~min}:-64.33 \pm 0.93 \mathrm{mV}, 60 \mathrm{~min}:$ $-64.21 \pm 0.27 \mathrm{mV})$, and the change is statistically significant $(\mathrm{p}=0.0654,0.0061,0.0174,0.0269$ for $15,30,45,60$ min vs. control; paired t test, $\mathrm{n}=10$ cells). Since the amplitude of depolarization is less than $3 \mathrm{mV}$, and the input resistance was not changed, we assume that the condition of neurons remained stable in $60 \mathrm{~min}$ of patching.

Neuronal excitability is determined by various types of transmembrane ionic current. To gain a sight of these ionic currents, whole-cell voltage clamping was performed to record the whole current and a steady-state $\mathrm{I}-\mathrm{V}$ relation was measured after offline $\mathrm{P} / \mathrm{N}$ subtraction (fig. 1c, d). This steady-state I-V relation measures the sum of the asymptotic value of all transmembrane currents, and it provides information about all persistent currents operating within a certain range of transmembrane potential. After HFS induction, the steady-state whole current was reduced significantly in the potential range of the above $-10 \mathrm{mV}$ (fig. $1 \mathrm{~d}$; $\mathrm{p}=0.031$; repeated measures ANOVA, $\mathrm{n}=16$ cells).

Dopamine Inhibits HFS-Induced LTP of Intrinsic Excitability

\section{HFS-Induced Increase in Excitability Was Inhibited} by DA Application

The aim of this study was to investigate how DA influences the activity-dependent intrinsic plasticity of CA1 hippocampal pyramidal neurons when HFS was applied to Schaffer collaterals. In our experiments, $20 \mu \mathrm{M}$ DA was applied. This concentration is commonly used for in vitro studies and is comparable with the effective DA concentration in vivo [37].

To study the effect DA might exert on the plasticity of excitability induced by HFS, $20 \mu \mathrm{M}$ DA was applied $2 \mathrm{~min}$ before HFS and then washed out 2 min after the end of HFS. In the presence of DA, both rheobase and mean firing rate (fig. $2 \mathrm{~b}$ ) showed no significant change after HFS (rheobase: $\mathrm{p}=0.7533,1,0.1199,0.2156$ for $15,30,45,60$ min vs. control; mean firing rate: $\mathrm{p}=0.6380,0.6583$, $0.3662,0.4097$ for $15,30,45,60$ min vs. control; paired $t$ test, $\mathrm{n}=13$ cells). Input resistance and resting membrane potential were not changed either (input resistance: $\mathrm{p}=$ $0.8532,0.9352,0.7980,0.8767$ for $15,30,45,60 \mathrm{~min}$ vs. control; resting membrane potential: $\mathrm{p}=0.5471,0.4114$, $0.2646,0.5996$ for $15,30,45,60$ min vs. control; paired $\mathrm{t}$ test, $\mathrm{n}=13$ cells). In addition, the steady-state whole current remained unchanged after HFS induction (fig. 2c, d; $\mathrm{p}=0.762$; repeated measures ANOVA, $\mathrm{n}=13$ cells).

It is rational to assume that this DA effect may result from the decrease in excitability instead of the interaction with the HFS induction of intrinsic plasticity. We hypothesized that the DA application alone is not sufficient to cause a significant decrease in excitability, since the application of DA was limited in less than $7 \mathrm{~min}$. To test this hypothesis, 11 neurons were recorded with 7-min DA bath application (which is similar to the experiment described above) but without HFS induction. Though the resting membrane potential was slightly depolarized after the short-term DA application $(\mathrm{p}=0.0111,0.0103$, $0.0896,0.0804$ for $15,30,45,60$ min vs. control; paired $\mathrm{t}$ test, $\mathrm{n}=11$ cells), no significant changes in rheobase, mean firing rate and input resistance after DA application were observed (fig. $2 \mathrm{e}$; rheobase: $\mathrm{p}=0.6811,0.6811$, $0.2815,0.1705$ for $15,30,45,60$ min vs. control; mean firing rate: $\mathrm{p}=0.5146,0.4841,0.1762,0.2066$ for $15,30,45$, 60 min vs. control; input resistance: $\mathrm{p}=0.1149,0.4238$, $0.7456,0.9410$ for $15,30,45,60$ min vs. control; paired $t$ test, $\mathrm{n}=11$ cells). These data suggested that DA abolishes the HFS-induced increase in excitability via interaction with HFS induction rather than merely decreasing the excitability. 


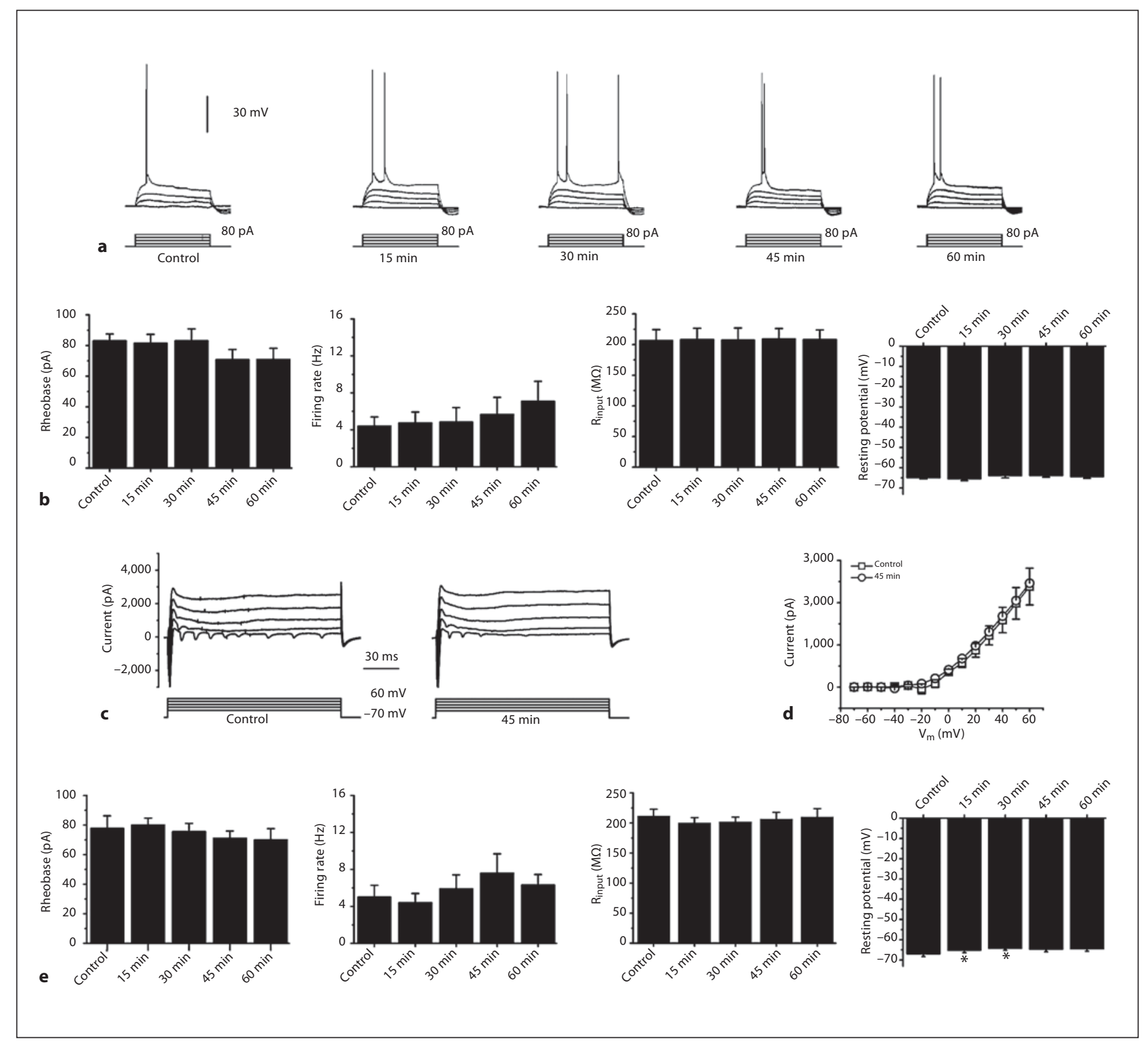

Fig. 2. DA-inhibited HFS-induced increase in excitability. a Recordings from a representative pyramidal neuron showing stable rheobase and mean firing rate after HFS induction when $20 \mu \mathrm{M}$ DA was present. Bottom lines show injected currents (in picoamperes). $\mathbf{b}$ Statistics of 13 neurons showed that rheobase, firing rate, input resistance and resting membrane potential were not changed by HFS induction when DA was present. c Whole-cell voltage clamp recordings from a representative pyramidal neuron showing whole current before (left) and $45 \mathrm{~min}$ after (right) HFS induc- tion when DA was present. Bottom lines show holding potentials (in millivolts). d Steady-state whole current did not change after HFS induction when $20 \mu \mathrm{M}$ DA was coapplied with the HFS. e Eleven neurons were recorded with 7-min DA bath application but without HFS induction. There was no significant change in rheobase, mean firing rate and input resistance but a slight depolarization in resting membrane potential. ${ }^{*} \mathrm{p}<0.05$; paired t-test, $\mathrm{n}=11$. 


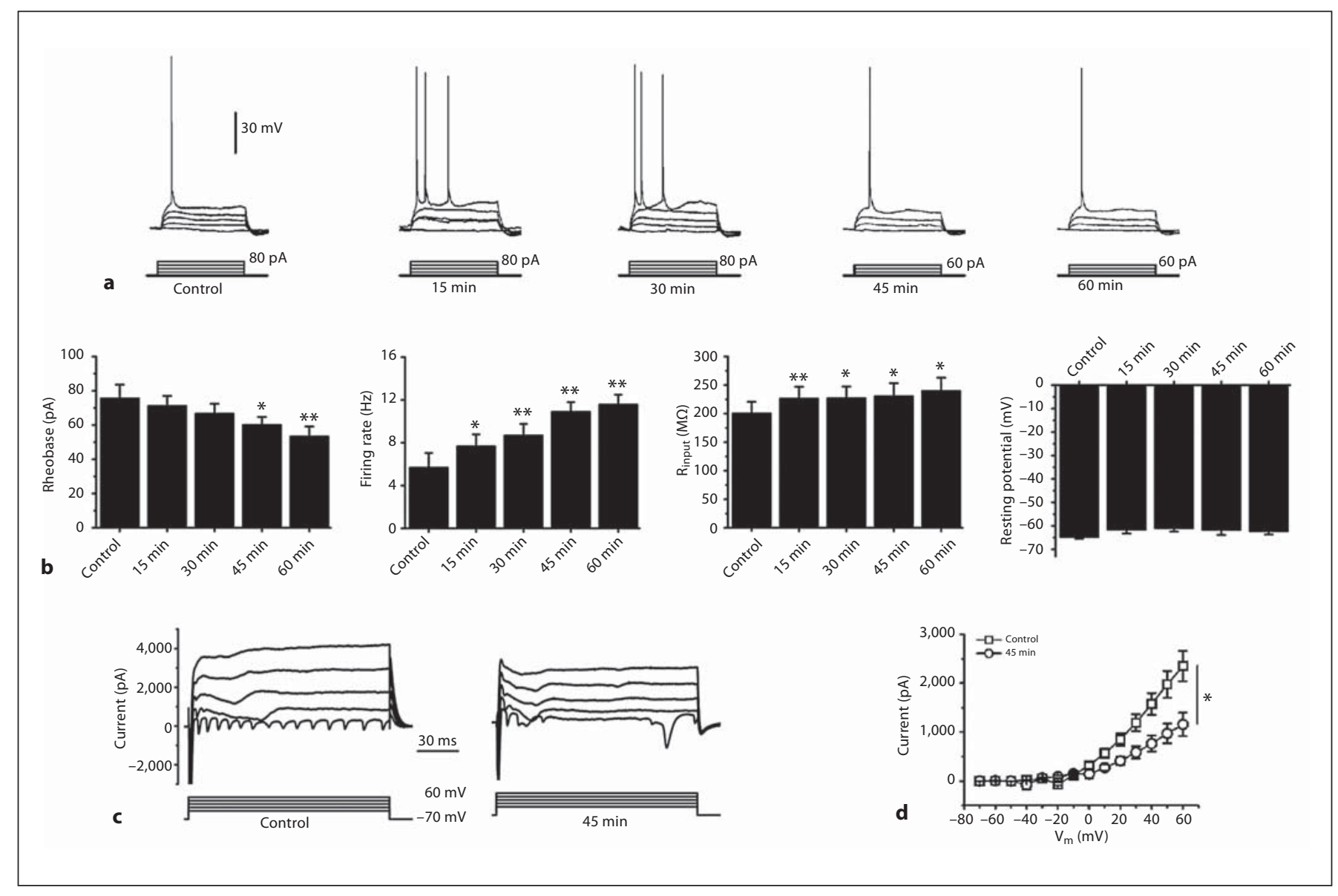

Fig. 3. Blockade of $\mathrm{D}_{1}$-like receptors abolishes the DA inhibition of HFS-induced intrinsic plasticity. a Recordings from a representative pyramidal neuron showing rescued decrease in rheobase and increase in mean firing rate after HFS induction when DA and SCH23390 were present. Bottom lines show injected currents (in picoamperes). b Statistics of 10 neurons showed that blockade of $\mathrm{D}_{1}$-like receptors rescued the decrease in rheobase and increase in firing rate and input resistance. In the presence of DA and SCH23390, the rheobase decreased 45 min after HFS induction,

\section{DA Inhibition of HFS-Induced Intrinsic Plasticity \\ Required $D_{1}$-Like Receptor Activation}

DA receptors are classified into 2 groups, $\mathrm{D}_{1}$-like receptors $\left(\mathrm{D}_{1} / \mathrm{D}_{5}\right.$ receptors), which activate adenylate cyclase, and $\mathrm{D}_{2}$-like receptors $\left(\mathrm{D}_{2} / \mathrm{D}_{3} / \mathrm{D}_{4}\right.$ receptors), which inhibit adenylate cyclase [38]. The activation of $\mathrm{D}_{1}$-like receptors has a central role in facilitating LTP induction and maintenance in many brain areas including the hippocampus [33]. To examine which subtype of DA receptor was responsible for DA inhibition of the HFS-induced intrinsic plasticity, a selective $\mathrm{D}_{1}$-like or $\mathrm{D}_{2}$-like antagonist was applied together with DA. When $10 \mu \mathrm{M}$ and the mean firing rate and input resistance increased significantly 15 min after HFS induction. ${ }^{*} \mathrm{p}<0.05,{ }^{* *} \mathrm{p}<0.01$, paired $\mathrm{t}$ test, versus control, $\mathrm{n}=10$. $\mathrm{c}$ Whole-cell voltage clamp recordings from a representative pyramidal neuron showing whole current before (left) and 45 min after (right) HFS induction when DA was present. Bottom lines show holding potentials (in millivolts). d Steady-state whole current decreased significantly 45 min after HFS in the presence of DA and SCH23390. ${ }^{*} \mathrm{p}<0.05$, repeated measures ANOVA, $\mathrm{n}=10$.

SCH23390, a selective $D_{1} / D_{5}$ receptor antagonist, was added to the perfusion solution $1 \mathrm{~min}$ before DA treatment, the HFS-induced decrease in rheobase and increase in mean firing rate were rescued (fig. $3 b$ ). The rheobase decreased significantly 45 min after HFS induction ( $\mathrm{p}=0.1690,0.1038,0.0232,0.0028$ for $15,30,45,60$ min vs. control; paired t test, $\mathrm{n}=10$ cells) and the mean firing rate increased significantly $15 \mathrm{~min}$ after application of HFS ( $\mathrm{p}=0.0400,0.0028,0.0001,0.0002$ for 15,30 , 45, 60 min vs. control; paired t test, $n=10$ cells). Input resistance also increased significantly $(\mathrm{p}=0.0027,0.0140$, $0.0223,0.0104$ for $15,30,45,60$ min vs. control; paired $t$ 


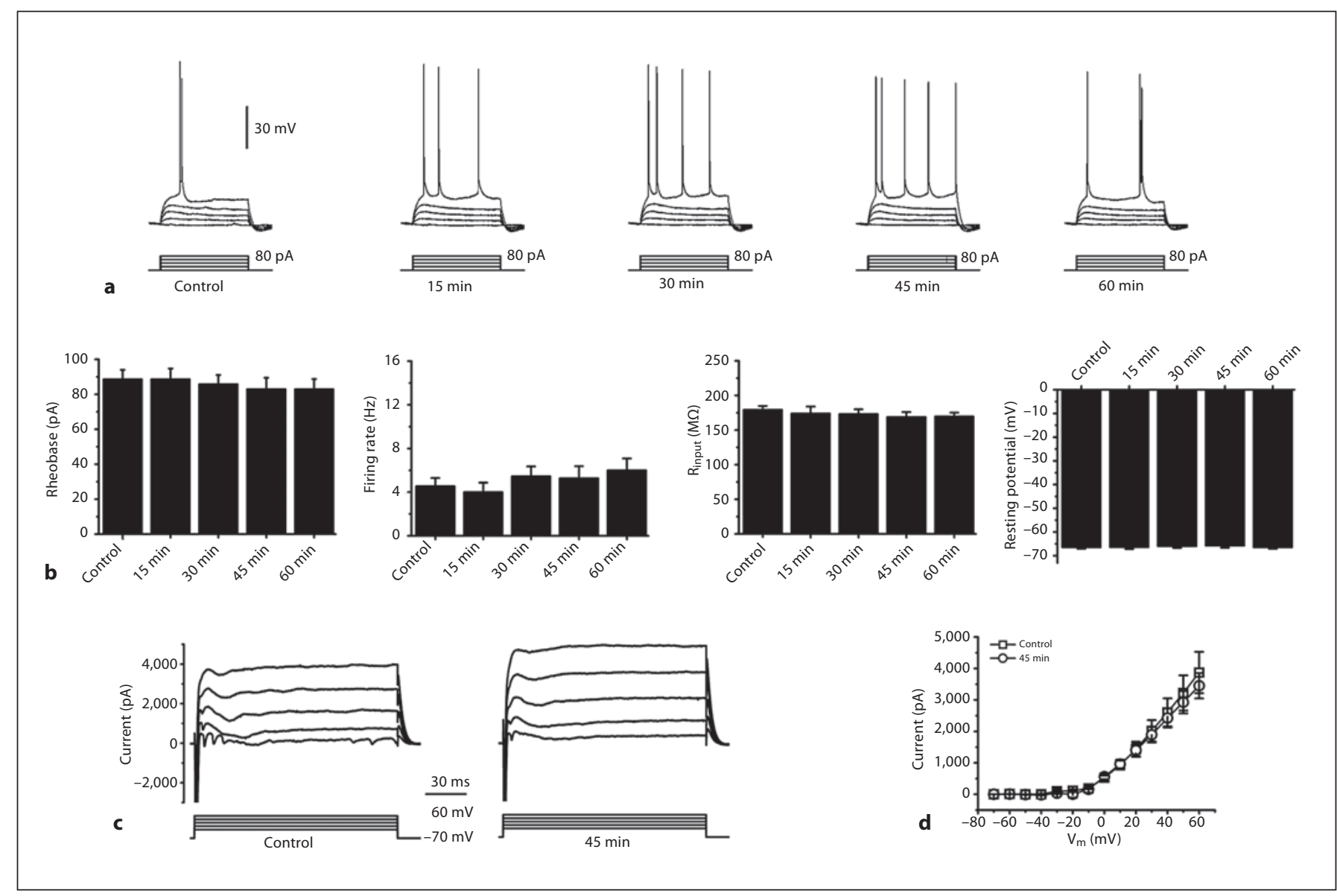

Fig. 4. Sulpiride has no effect on the DA inhibition of HFS-induced intrinsic plasticity. a Recordings from a representative pyramidal neuron showing stable rheobase and mean firing rate after HFS induction when DA and sulpiride were present. Bottom lines show injected currents (in picoamperes). b Statistics of 14 neurons showed that rheobase, firing rate, input resistance and resting membrane potential were not changed by HFS induction when DA and sulpiride were present. c Whole-cell voltage clamp recordings from a representative pyramidal neuron showing whole current before (left) and 45 min after (right) HFS induction when DA was present. Bottom lines show holding potentials (in millivolts). d Steady-state whole current did not change after HFS induction in the presence of DA and sulpiride. test, $\mathrm{n}=10$ cells). The decrease in steady-state whole current was also rescued (fig. $3 c, d ; p=0.022$; repeated measures ANOVA, $\mathrm{n}=10$ cells). The resting membrane potential was not changed $(\mathrm{p}=0.0827,0.0682,0.2560,0.1194$ for $15,30,45,60$ min vs. control; paired t test, $n=10$ cells).

To determine the role of $\mathrm{D}_{2}$-like receptors in DA inhibition of the HFS-induced intrinsic plasticity, we tested the effect of the $\mathrm{D}_{2}$-like receptor-selective antagonist sulpiride $(50 \mu \mathrm{M})$ on DA inhibition of intrinsic excitability induced by HFS. No significant change was observed in rheobase, mean firing rate, input resistance and the resting membrane potential (fig. $4 \mathrm{~b}$; rheobase: $\mathrm{p}=1,0.5470$, $0.3356,0.3019$ for $15,30,45,60$ min vs. control; mean fir- ing rate: $\mathrm{p}=0.4997,0.2192,0.4953,0.0872$ for $15,30,45$, $60 \mathrm{~min}$ vs. control; input resistance: $\mathrm{p}=0.5833,0.3449$, $0.0968,0.0849$ for $15,30,45,60$ min vs. control; resting membrane potential: $\mathrm{p}=0.9230,0.5157,0.3839,0.4492$ for $15,30,45,60$ min vs. control; paired t test, $\mathrm{n}=14$ cells). In addition, the steady-state whole current remained unchanged after HFS induction (fig. 4c, d; $p=0.694$; repeated measures ANOVA, $\mathrm{n}=14$ cells).

To further assess the difference between groups under different treatments, rheobase, mean firing rate and input resistance of 4 groups (HFS, HFS-DA, HFSSCH23390-DA, HFS-sulpiride-DA) were normalized by their before-HFS value and were illustrated together in 


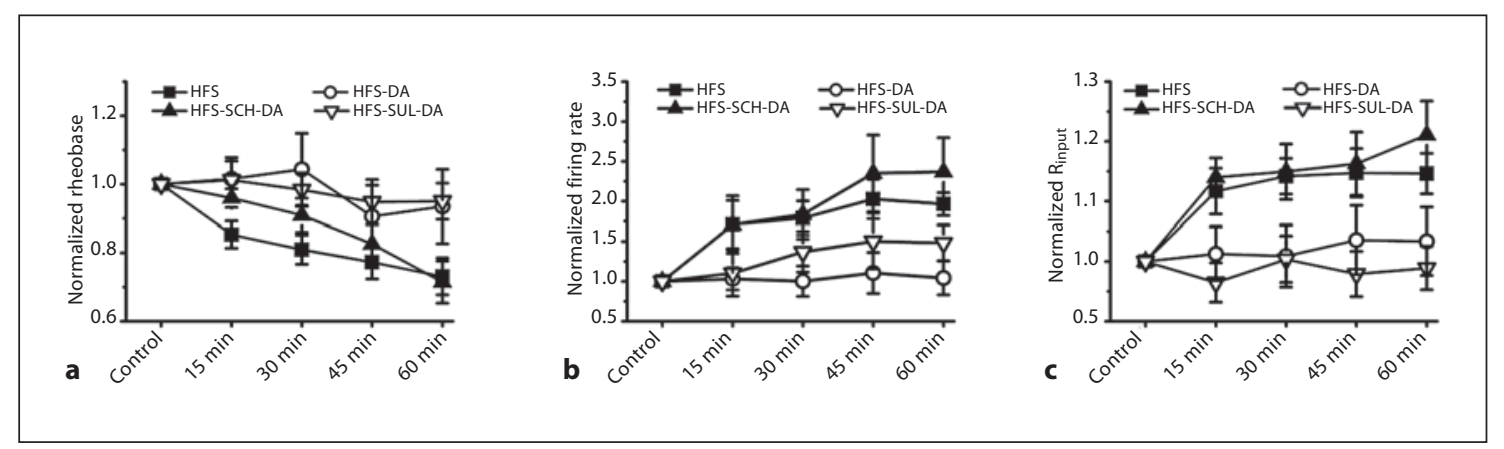

Fig. 5. Comparison of normalized data from 4 groups. a Normalized rheobases of the HFS-DA group were significantly different from those of the HFS group $(\mathrm{p}<0.05)$. b There were significant differences in the normalized mean firing rate between HFS-DA and HFS groups $(\mathrm{p}<0.05)$ and between HFS-SCH-DA and HFS-DA groups $(\mathrm{p}<0.01)$. $\mathrm{c}$ There were significant differences in the normalized input resistance between HFS-DA and HFS groups $(\mathrm{p}<0.05)$ and between HFS-SCH-DA and HFS-DA groups $(\mathrm{p}<0.05$; repeated measures ANOVA, post-hoc least significant difference test).

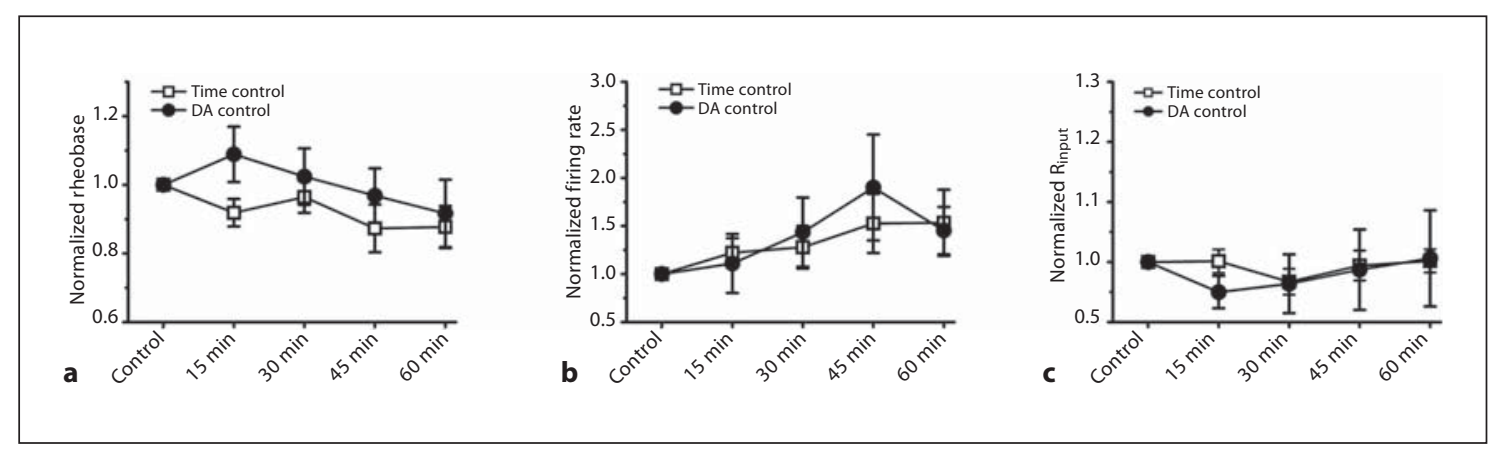

Fig. 6. Comparison of normalized data from time control and DA control groups. There was no significant difference in either rheobase $(\mathbf{a} ; \mathrm{p}=0.329)$, mean firing rate $(\mathbf{b} ; \mathrm{p}=0.839)$ or input resistance $(\mathbf{c} ; \mathrm{p}=0.810)$ between time control and DA control groups (repeated measures ANOVA).

figure 5. Repeated measures ANOVA was performed on the normalized data to compare these groups. There was a significant difference between these 4 groups in rheobase, mean firing rate and input resistance (rheobase: $\mathrm{p}=$ 0.047 ; mean firing rate: $\mathrm{p}=0.036$; input resistance: $\mathrm{p}=$ 0.003). Post-hoc comparisons using the least significant difference test revealed that the HFS-DA group was significantly different from the HFS group in rheobase $(\mathrm{p}=$ $0.021)$, mean firing rate $(\mathrm{p}=0.046)$ and input resistance ( $\mathrm{p}=0.036)$. The HFS-SCH23390-DA group was significantly different from the HFS-DA group in mean firing rate $(\mathrm{p}=0.006)$ and input resistance $(\mathrm{p}=0.024)$ but not in rheobase $(\mathrm{p}=0.18)$. [Note that $\mathrm{SCH} 23390$ only rescued the rheobase decrease at a later time point (fig. $3 \mathrm{~b}$ ), the post hoc test failed to reveal a significant difference be- tween HFS-DA and HFS-SCH23390-DA groups in rheobase (fig. 5a).] There was no significant difference in rheobase $(p=0.957)$, mean firing rate $(p=0.331)$ or input resistance $(\mathrm{p}=0.474)$ between the HFS-sulpiride-DA group and HFS-DA group. The results suggested that the HFS-induced intrinsic plasticity of pyramidal neurons is significantly changed by DA, and that this DA effect is $\mathrm{D}_{1}$-like receptor dependent.

To further determine the effect of short-term DA application on neurons in the absence of HFS induction, data observed from time control (fig. 1e) and DA control (fig. 2e) experiments were also normalized and compared (fig. 6) using repeated measures ANOVA. There was no significant difference in rheobase $(\mathrm{p}=0.329)$, mean firing rate $(\mathrm{p}=0.839)$ or input resistance $(\mathrm{p}=0.810)$ between 
these two groups, indicating that a 7-min bath of DA had no effect on the excitability of neurons when HFS induction was absent. This further confirmed that DA inhibited the HFS-induced increase in excitability through interaction with HFS induction rather than changed the excitability by itself.

\section{Discussion}

The hippocampus receives rich dopaminergic innervation from the mesocorticolimbic system. The effects of DA on synaptic plasticity as well as excitability of the hippocampus have been extensively investigated. However, little is known about whether the DA system interacts with the activity-dependent intrinsic plasticity of pyramidal neurons, which is considered a supplementary mechanism for learning and memory. Here we report that application of DA during presynaptic HFS induction inhibited the increased excitability induced by HFS alone. This result suggests that DA interacts with the activitydependent intrinsic plasticity of pyramidal neurons. This effect implies a new mechanism that DA might employ to modulate the hippocampus.

How does $\mathrm{D}_{1}$-like receptor signaling influence the HFS-induced intrinsic plasticity? Experimental evidence has shown that in hippocampal CA1 pyramidal neurons, the induction of activity-dependent LTP of intrinsic excitability requires activation of $\mathrm{N}$-methyl-D-aspartate (NMDA) receptors, subsequent $\mathrm{Ca}^{2+}$ increase in spines and local dendrites, activation of CaM kinase II, and protein synthesis activity [8]. This suggests that the induction mechanism for intrinsic plasticity shares the similar pathways with synaptic plasticity, which is the NMDA receptor/ $\mathrm{Ca}^{2+} / \mathrm{CaM}$ kinase pathway. It has been found that DA partially inhibits NMDA receptor-mediated synaptic currents $[34,39,40]$. One would assume that this inhibition of NMDA receptor-mediated currents by DA would cause less calcium influx and, thus, attenuate activity-dependent intrinsic excitability.

Furthermore, the intrinsic plasticity should eventually result from changes in the kinetics, number and distribution of ion channels. Our results indicate that HFS-induced potentiation of intrinsic excitability was accompanied by a decrease in steady-state whole current over -10 $\mathrm{mV}$, which is a net outward current. DA abolished this decrease in steady-state whole current, which was dependent on activation of $\mathrm{D}_{1}$-like receptors. The changes in input resistance, which measures the permeability of a membrane to charged ions, were consistent with the changes in the steady-state whole currents. Although which channels and how these channels are modified by HFS induction and DA remains to be explored, it could be assumed that this decrease in outward whole current during membrane depolarization would contribute to the potentiation of excitability.

Both HFS-induced LTP of intrinsic excitability and the DA effect may involve multiple processes. Many channels may be modified and the processes of these modulations may function in different time scales. In our experiments, SCH23390 rescued the DA effect on firing rate and input resistance at early time points $(15 \mathrm{~min}$ ) but rescued the decline of rheobase at a later time point ( 45 $\mathrm{min}$ ), indicating that a different mechanism underlies the changes in rheobase and other measures.

The higher cognitive function of the brain depends on its ability to integrate the information collected from the exterior environment. Information flow and processing in the neural network are primarily mediated by action potential propagation through neurons and the communication between neurons by synapses. Although it is widely accepted that the synapse is an important target, which is subject to activity-dependent persistent modulation and mediates learning and memory, the intrinsic property of neurons also undergoes activity-dependent plasticity to enhance the input-output functions of neurons, and thus plays an important role in learning and memory. The hippocampus, which has a key role in learning and memory, receives extensive dopaminergic projections. Our results suggest that the activity-dependent intrinsic excitability is also modulated by DA, which leads to a new insight into neural circuit functions underpinning rewarding and reinforcement of learning.

\section{Acknowledgements}

This work was supported by the National Natural Science Foundation of China (grants No. 81171264, 30900443 and 31040037).

\section{Disclosure Statement}

The authors declare that they have no conflicts of interest. 


\section{References}

1 Nataraj K, Turrigiano G: Regional and temporal specificity of intrinsic plasticity mechanisms in rodent primary visual cortex. J Neurosci 2011;31:17932-17940.

-2 Nataraj K, Le Roux N, Nahmani M, Lefort S, Turrigiano G: Visual deprivation suppresses $\mathrm{L}_{5}$ pyramidal neuron excitability by preventing the induction of intrinsic plasticity. Neuron 2010;68:750-762.

>3 Kang J, Kang N, Yu Y, Zhang J, Petersen N, Tian GF, Nedergaard M: Sulforhodamine 101 induces long-term potentiation of intrinsic excitability and synaptic efficacy in hippocampal CA1 pyramidal neurons. Neuroscience 2010;169:1601-1609.

$\checkmark 4$ Aizenman CD, Akerman CJ, Jensen KR, Cline HT: Visually driven regulation of intrinsic neuronal excitability improves stimulus detection in vivo. Neuron 2003;39:831842 .

5 Zhang W, Linden DJ: The other side of the engram: experience-driven changes in neuronal intrinsic excitability. Nat Rev Neurosci 2003;4:885-900.

$\checkmark 6$ Daoudal G, Debanne D: Long-term plasticity of intrinsic excitability: learning rules and mechanisms. Learn Mem 2003;10:456-465.

$>7$ Sourdet V, Russier M, Daoudal G, Ankri N, Debanne D: Long-term enhancement of neuronal excitability and temporal fidelity mediated by metabotropic glutamate receptor subtype 5. J Neurosci 2003;23:1023810248.

$>_{8}$ Xu J, Kang N, Jiang L, Nedergaard M, Kang $\mathrm{J}$ : Activity-dependent long-term potentiation of intrinsic excitability in hippocampal CA1 pyramidal neurons. J Neurosci 2005;25: 1750-1760.

$>9$ Jung SC, Hoffman DA: Biphasic somatic Atype K channel downregulation mediates intrinsic plasticity in hippocampal CA1 pyramidal neurons. PLoS One 2009;4:e6549.

10 Ganguly K, Kiss L, Poo M: Enhancement of presynaptic neuronal excitability by correlated presynaptic and postsynaptic spiking. Nat Neurosci 2000;3:1018-1026.

-11 Li CY, Lu JT, Wu CP, Duan SM, Poo MM: Bidirectional modification of presynaptic neuronal excitability accompanying spike timing-dependent synaptic plasticity. Neuron 2004;41:257-268.

-12 Fan Y, Fricker D, Brager DH, Chen X, Lu HC, Chitwood RA, Johnston D: Activity-dependent decrease of excitability in rat hippocampal neurons through increases in $\mathrm{I}(\mathrm{h})$. Nat Neurosci 2005;8:1542-1551.

13 Brager DH, Johnston D: Plasticity of intrinsic excitability during long-term depression is mediated through mGluR-dependent changes in $\mathrm{I}(\mathrm{h})$ in hippocampal CA1 pyramidal neurons. J Neurosci 2007;27:1392613937.
14 Bliss TV, Lomo T: Long-lasting potentiation of synaptic transmission in the dentate area of the anaesthetized rabbit following stimulation of the perforant path. J Physiol 1973; 232:331-356.

15 Aizenman CD, Linden DJ: Rapid, synaptically driven increases in the intrinsic excitability of cerebellar deep nuclear neurons. Nat Neurosci 2000;3:109-111.

16 Armano S, Rossi P, Taglietti V, D’Angelo E: Long-term potentiation of intrinsic excitability at the mossy fiber-granule cell synapse of rat cerebellum. J Neurosci 2000;20: 5208-5216.

17 Cudmore RH, Turrigiano GG: Long-term potentiation of intrinsic excitability in LV visual cortical neurons. J Neurophysiol 2004; 92:341-348.

18 Frick A, Magee J, Johnston D: LTP is accompanied by an enhanced local excitability of pyramidal neuron dendrites. Nat Neurosci 2004;7:126-135.

19 Schultz W: Multiple dopamine functions at different time courses. Annu Rev Neurosci 2007;30:259-288.

20 Bach ME, Barad M, Son H, Zhuo M, Lu YF, Shih R, Mansuy I, Hawkins RD, Kandel ER: Age-related defects in spatial memory are correlated with defects in the late phase of hippocampal long-term potentiation in vitro and are attenuated by drugs that enhance the cAMP signaling pathway. Proc Natl Acad Sci USA 1999;96:5280-5285.

21 Gasbarri A, Sulli A, Innocenzi R, Pacitti C, Brioni JD: Spatial memory impairment induced by lesion of the mesohippocampal dopaminergic system in the rat. Neuroscience 1996;74:1037-1044.

22 Gasbarri A, Packard MG, Campana E, Pacitti C: Anterograde and retrograde tracing of projections from the ventral tegmental area to the hippocampal formation in the rat. Brain Res Bull 1994;33:445-452.

23 Goldsmith SK, Joyce JN: Dopamine $\mathrm{D}_{2}$ receptor expression in hippocampus and parahippocampal cortex of rat, cat, and human in relation to tyrosine hydroxylase-immunoreactive fibers. Hippocampus 1994;4:354-373.

24 Scoville WB, Milner B: Loss of recent memory after bilateral hippocampal lesions. J Neurol Neurosurg Psychiatry 1957;20:11-21.

25 Eichenbaum H: Hippocampus: cognitive processes and neural representations that underlie declarative memory. Neuron 2004; 44:109-120.

26 Biscoe TJ, Straughan DW: Micro-electrophoretic studies of neurones in the cat hippocampus. J Physiol 1966;183:341-359.

27 Herrling PL: The membrane potential of cat hippocampal neurons recorded in vivo displays four different reaction-mechanisms to iontophoretically applied transmitter agonists. Brain Res 1981;212:331-343.
28 Stanzione P, Calabresi P, Mercuri N, Bernardi G: Dopamine modulates CA1 hippocampal neurons by elevating the threshold for spike generation: an in vitro study. Neuroscience 1984;13:1105-1116.

29 Pockett S: Dopamine changes the shape of action potentials in hippocampal pyramidal cells. Brain Res 1985;342:386-390.

30 Malenka RC, Nicoll RA: Dopamine decreases the calcium-activated afterhyperpolarization in hippocampal CA1 pyramidal cells. Brain Res 1986;379:210-215.

31 Berretta N, Berton F, Bianchi R, Capogna M, Francesconi W, Brunelli M: Effects of dopamine, D-1 and D-2 dopaminergic agonists on the excitability of hippocampal CA1 pyramidal cells in guinea pig. Exp Brain Res 1990;83:124-130.

32 Lemon N, Manahan-Vaughan D: Dopamine $\mathrm{D}_{1} / \mathrm{D}_{5}$ receptors gate the acquisition of novel information through hippocampal longterm potentiation and long-term depression. J Neurosci 2006;26:7723-7729.

33 Otmakhova NA, Lisman JE: $\mathrm{D}_{1} / \mathrm{D}_{5}$ dopamine receptor activation increases the magnitude of early long-term potentiation at CA1 hippocampal synapses. J Neurosci 1996;16:7478-7486.

34 Zhang JC, Lau PM, Bi GQ: Gain in sensitivity and loss in temporal contrast of STDP by dopaminergic modulation at hippocampal synapses. Proc Natl Acad Sci USA 2009;106: 13028-13033.

35 Chen Z, Fujii S, Ito K, Kato H, Kaneko K, Miyakawa $\mathrm{H}$ : Activation of dopamine $\mathrm{D}_{1}$ receptors enhances long-term depression of synaptic transmission induced by low frequency stimulation in rat hippocampal CA1 neurons. Neurosci Lett 1995;188:195-198.

36 Mockett BG, Guevremont D, Williams JM, Abraham WC: Dopamine $\mathrm{D}_{1} / \mathrm{D}_{5}$ receptor activation reverses NMDA receptor-dependent long-term depression in rat hippocampus. J Neurosci 2007;27:2918-2926.

37 Garris PA, Wightman RM: Different kinetics govern dopaminergic transmission in the amygdala, prefrontal cortex, and striatum: an in vivo voltammetric study. J Neurosci 1994; 14:442-450.

38 Missale C, Nash SR, Robinson SW, Jaber M, Caron MG: Dopamine receptors: from structure to function. Physiol Rev 1998;78: 189-225.

39 Otmakhova NA, Lisman JE: Dopamine selectively inhibits the direct cortical pathway to the CA1 hippocampal region. J Neurosci 1999;19:1437-1445.

40 Lee FJ, Xue S, Pei L, Vukusic B, Chery N, Wang Y, Wang YT, Niznik HB, Yu XM, Liu F: Dual regulation of NMDA receptor functions by direct protein-protein interactions with the dopamine $\mathrm{D}_{1}$ receptor. Cell 2002; 111:219-230. 